\title{
Anaferon, released-active from of antibodies to IFN $\gamma$, as an effective medicine for treatment and prophylaxis of a wide spectrum of infections
}

Tarasov SA, Kachanova MV, Gorbunov EA*, Zabolotneva JA, Ertuzun IA, Belopolskaya MV, Borodavkina MV, Dugina JL, and Epstein OI OOO "NPF “MATERIA MEDICA HOLDING" 3rd Samotyochny per: 9, 127473, Moscow, Russian Federation

\begin{abstract}
Anaferon, released-active from of antibodies to interferon-gamma, is an antiviral drug with immunomodulating activity. The long-term experience proved its efficacy and safety in the treatment and prophylaxis of a wide spectrum of viral and bacterial infections. The key mechanisms of anaferon action are the regulation of endogenous interferons, in particular interferon-gamma: induction conformational changes in interferon-gamma regions that play essential roles in interferongamma specific binding to its receptor, resulting in activation of the interferon-gamma signaling pathway and antiviral activity. Excellent safety profile, possibility of its combination with other medicines, absence of withdrawal have made it a drug of choice for the treatment and prophylaxis of various infections.
\end{abstract}

To date, viral infections are the leading cause of morbidity worldwide, and, as predicted by the WHO, the role of infection in the overall disease structure will only become greater in the XXI century [1].

The range of available antiviral drugs is fairly large. The treatment for viral infections is a complex one and involves not only etiological therapies, i.e. directly targeting the virus, but also immunomodulatory agents, which ameliorate immune defects resulting from viral infections, as well as symptomatic (with effects on general viral illness symptoms, such as fever, muscle aches, cough, etc.) and pathogenetic agents used in intoxication, dehydration, or allergic reactions.

Despite all this, though, it is still a long way to go before the final solution to the issue of effective antiviral prevention and treatment can be found. The reason for this is the high contagiousness and dissemination rapidity of causative agents, abundance of antigenically independent viruses, variation in the antigenic properties of viruses, high likelihood of mixed infection, rapidly developing drug resistance, risk of secondary immunodeficiency, and specificity of action of most therapies [2].

Today, given the high priority of treating viral infections alongside with vaccination, it seems an important goal to search for new antiviral agents with novel mechanisms of action and favorable safety profiles, which could be effectively used in treating and preventing a wide range of viral infections, managing mixed infections and preventing immunosuppression. One of the new-generation antivirals is a drug containing released-active form of antibodies to interferon-gamma (anaferon). Released-active form of antibodies is manufactured based on a novel patented biotechnological platform (US Patent 8535664, 2013), which is consistent with routine methods described in the $7^{\text {th }}$ Edition of the European Pharmacopoeia (general monographs 1038 and 2371).

This paper contains an overview of clinical trials conducted with the purpose to investigate the efficacy and safety of anaferon in the treatment and prevention of viral infections, and some considerations on the drug's possible mechanisms of action.

One of the key anaferon's mechanisms of action is the regulation of endogenous interferons (IFNs), in particular interferon-gamma (IFN $\gamma$ ): the drug induces spontaneous and mitogen-stimulated production of type I and II IFNsas early as within 24 hours of the first dose. IFN $\gamma$ is an immunomodulatory cytokine that orchestrates a number of cellular processes via transcription regulation of numerous genes. IFN $\gamma$ exhibits pleiotropic biological properties, including the ability to induce the expression of MHC 1 and 2 antigens and Fc receptors, activate monocytes, and stimulate NK cell activity. It functions as a regulator of immunoglobulin synthesis, including Ig class switching. The biological activity of IFN $\gamma$ is mediated through specific cell receptors and the intracellular protein kinase cascade (Figure 1), which results in an activation of related transcription factors and transcription of an entire gene family that encode virus resistance factors and complementary cytokines (Table 1) [3].

Anaferon belongs to the class of the products that common feature is that they directly modify the initial substance (or biological molecules which structurally are similar to the initial substance) by changing its spatial structure resulting in alteration of its physical, chemical, and biological properties [4]. These products have been referred to as "released-active" because their activity is released during the technological process. As it was mentioned above, IFN $\gamma$ is a primary target of anaferon. Data obtained using ELISA and piezoelectric

Correspondence to: Gorbunov EA, 47-1, Trifonovskaya Street, 129272 Moscow, Russian Federation, Tel: +7 495276 1571, ext. 119; Fax: +7 495276 1571, ext. 001; E-mail: gorbunovea@materiamedica.ru

Key words: antiviral; immunomodulation; released-activity.

Received: October 07, 2016; Accepted: October 17, 2016; Published: October 19,2016 
Table 1. Major biological properties of IFN $\gamma$.

\begin{tabular}{|c|c|c|c|}
\hline Action & Effect & Mechanism of action & Cells \\
\hline Antiviral & Inhibition of virus replication & Induction of 2'-5'-oligoadenylate synthetase, protein kinase and $\mathrm{Mx} 1$ protein & Most cell types \\
\hline Antimicrobial & $\begin{array}{l}\text { Macrophage production of toxins (NO, } \\
\mathrm{H}_{2} \mathrm{O}_{2}, 2,3 \text {-dioxygenase, etc.) Inhibition of } \\
\text { invasionprocesses and intracellular replication } \\
\text { of microorganisms }\end{array}$ & $\begin{array}{l}\text { Promotion of NO oxygenase production, activation of oxidative processes and } \\
\text { upregulation of cytochrome b558. Induction of NF-kB (factor that activates } \\
\text { gene expression), resulting in immunoregulatory protein translation. Induction } \\
\text { of 2,3-dioxygenase, which reduces L-tryptophan level and intracellular ion } \\
\text { concentration. }\end{array}$ & Most cell types \\
\hline Specific immunity & Activation of defense mechanisms & $\begin{array}{l}\text { Induction of MHC class } 2 \text { antigens. Upregulation of MHC class } 1 \text { antigens. } \\
\text { Upregulation of Fc receptors. Ig production }\end{array}$ & $\begin{array}{l}\text { Many tissues and most } \\
\text { cell types, macrophages, } \\
\text { lymphocytes, B cells }\end{array}$ \\
\hline Innate immunity & Activation of defense mechanisms & $\begin{array}{l}\text { Promotion of IL-1, CSF and TNF production. Downregulation of the complement } \\
\text { C3b receptor }\end{array}$ & Macrophages, T cells \\
\hline Adhesion & Strengthening of cell-cell bonding & $\begin{array}{l}\text { Upregulation of surface ICAM-1. Inhibition of collagen synthesis. Stimulation of } \\
\text { fibronectin synthesis }\end{array}$ & $\begin{array}{l}\text { Endothelial cells, fibroblasts, } \\
\text { macrophages }\end{array}$ \\
\hline $\begin{array}{l}\text { Cell growth and } \\
\text { differentiation }\end{array}$ & $\begin{array}{l}\text { Targeted inhibition of malignant cell } \\
\text { proliferation, activation of NK cells }\end{array}$ & $\begin{array}{l}\text { Up- or downregulation of the c-myc oncogene. Downregulation of EGF receptors } \\
\text { Induction of MHC class } 2 \text { antigens }\end{array}$ & $\begin{array}{l}\text { Many cell types, epithelial } \\
\text { cells, immunological cells }\end{array}$ \\
\hline
\end{tabular}

immunosensors evidences that anaferon is able to modify IFN $\gamma$ affinity to specific antibodies to IFN $\gamma[5,6]$. Using NMR it was shown that the drug induces conformational changes in IFN $\gamma$ regions that play essential roles in IFN $\gamma$ specific binding to its receptor, resulting in activation of the IFN $\gamma$ signaling pathway and antiviral activity [4]. Anaferon acts as positive allosteric IFN $\gamma$ receptor modulator: the level of IFN $\gamma$ binding to the receptor was increased by over $50 \%$ as a result of improved ligand-receptor interaction and enhanced expression of IFN $\gamma$ receptors on target cell surfaces [4].

Therefore, anaferon is capable of potentiating the key biological effects of IFN $\gamma$.

Preventive and/or therapeutic efficacy and safety of anaferon has been studied with respect to a varied number of infections in controlled randomised clinical trials, facilitated by a number of the leading health institutions of Russia and Ukraine.

The randomised, double-blind placebo-controlled and comparative clinical trials involved over 5500 patients, the majority of whom (due to special relevance of viral infections in the pediatric population) were children aged from 1 to 17 years (including chronically ailing children and children concomitant diseases).

For therapeutic efficacy observations of anaferon, the patients were enrolled during the acute phase of illness characterised by marked clinical symptoms. The drug was administered in therapeutic doses (1 tablet every 30 minutes for the first two hours, followed, on the same day and onward, by 1 tablet three times daily) in combination with conventional therapies. The therapeutic treatment lasted for at least 5 days and varied with the type and severity of viral infection. Treatment efficacy was evaluated according to the duration of major clinical signs and symptoms; some patients were tested for indices of immune status and interferon response.

For preventive efficacy evaluation, the prescribed dose was 1 tablet once daily throughout the epidemic season. Preventive effects were evaluated according to changes in the incidence of infection.

Clinical efficacy and safety of anaferon for the treatment and prevention of the most prevalent infections - acute viral respiratory infections (viral ARIs) and influenza, has been evaluated in a multicenter trial and 5 randomised trials facilitated by Russia's top health institutions.

These studies have shown a marked therapeutic and preventive efficacy of anaferon in managing influenza and other viral ARIs in

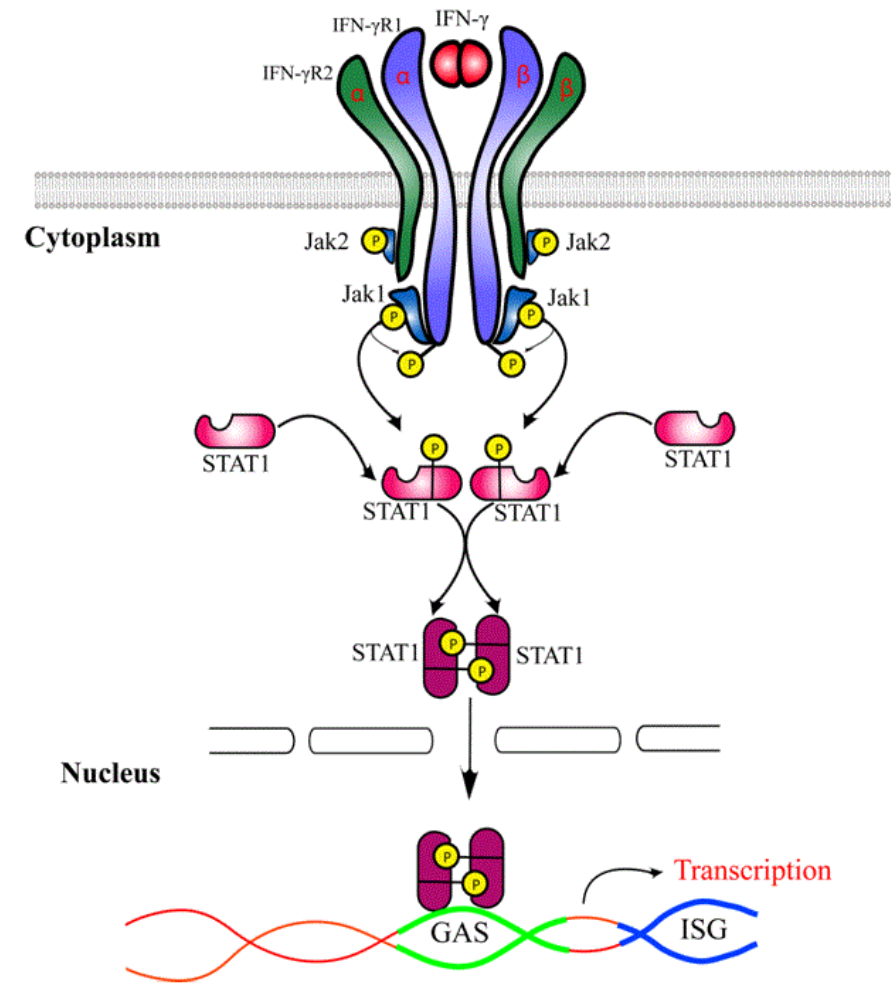

Figure 1. IFN $\gamma$ receptor and IFN $\gamma$-initiated intracellular signaling cascade.

children including infants in the first year of life [7-10]. Preventive administration of anaferon in pre- and post-vaccination periods was shown to increase the immunological effectiveness of vaccine, provide non-specific prevention of viral ARIs and influenza during the development of post-vaccination immunity, and prevent intercurrent illness post vaccination [11].

Notably, anaferon is also effective in infections caused by respiratory syncytial virus, which are more frequently (compared to other viral ARIs) associated with lower respiratory tract complications, and are not presently addressed by any specific treatments [12].

The drug's high safety, coupled with almost no contraindications, and capacity to reduce the occurrence of bacterial complications suggests that anaferon can be effectively used for the treatment of viral infections in children with secondary immunodeficiencies or with accompanying pathology. Thus, anaferon has proven beneficial for the 
prevention of viral ARIs in immunocompromised infected children: the treatment was associated with reduced incidence of illness and lower number of recurrent ARI cases as compared to the control group [13].

Anaferon's effects have been demonstrated in preventive and rehabilitative treatment of chronically ill children, who are at high risk due to compromised immunity. Anaferon administration resulted in a substantial decrease in the incidence of respiratory illness and reduced severity of related clinical symptoms [14].

There is data providing reliable evidence of anaferon's efficacy in a combined therapeutic and preventive treatment of viral ARIs in asthmatic children. Anaferon administered as part of the combination drug regimen was shown to reduce the occurrence of asthmatic attacks and improve the quality of care for atopic patients during epidemiologically unfavourable periods [15].

Clinical efficacy of anaferon in herpesvirus infections, which are among poorly controlled ones, has been demonstrated in a number of ramdomised studies. The drug was shown effective against 4 out of the 8 herpesviruses pathogenic for humans. Anaferon results in the elimination of herpes simplex virus in non-symptomatic host patients. It substantially decreases the duration of symptoms in varicella (fever duration, development of new lesions and itching) [16] and infectious mononucleosis (duration of sore throat, lymphadenopathy, Banti's syndrome) [17], and the occurrence of bacterial complications.

Anaferon is well compatible with specific anti-herpes-virus therapies (acyclovir, valacyclovir), which, together with the former, provide an effective combination for resolving both systemic and topical symptoms of recurrent genital herpes [18], managing recurrent ocular herpes infections [19], and treating infectious mononucleosis [20].

Anaferon's efficacy in combination treatment for acute viral intestinal infections (viral AIIs) due to caliciviruses, rotaviruses, and coronaviruses has been evaluated in 3 randomised controlled trials. Anaferon administered as part of a standard anti-AII regimen resulted in a statistically significant shortening in the duration of major symptoms, i.e., fever, diarrhea, vomiting. Viral AIIs are among the most common viral infections (next to viral ARIs); no specific therapies are currently available for these infections and their treatment is based only on pathogenetic agents. Therefore, anaferon's efficacy assessed against viral AII is highly relevant to medical practice.

The efficacy of anaferon for preventing infectious diseases of the nervous system has been evidenced by clinical data obtained in patients receiving emergency preventive treatment for tick-borne encephalitis (TBE), the urgency of which is associated with a high death rate (about $20 \%$ ). As a results of a 21-day anaferon administration, no disease was developed by any of the children in the test group, unlike those in the comparison group (children receiving prophylactic anti-TBE immunoglobulin), and more than a three-order reduction was observed in the number of patients for whom the TBE antigen was isolated following a month after the bite. Thus, anaferon has a higher efficacy in managing tick-borne encephalitis as compared to conventional antiserum prophylaxis [21].

There has also been clinical evidence of anaferon's beneficial effect on interferon status, peripheral blood lymphocyte subsets, mucosal production of secretory IgA, and serum IgE levels, as reported in patients with viral infections.
The long-term experience of anaferon's application has proven its efficacy for the treatment and/or prevention of a wide range of infectious diseases of various etiologies as well as mixed infections:

- Acute viral respiratory infections caused by influenza virus $\mathrm{A}$ (including the $\mathrm{A} / \mathrm{H} 5 \mathrm{~N} 1$ and $\mathrm{A} / \mathrm{H} 1 \mathrm{~N} 1$ flu viruses) and $\mathrm{B}$, adenovirus, respiratory syncytial virus, coronavirus, parainfluenza virus, etc.;

- Herpesvirus infections caused by varicella virus, Epstein-Barr virus, herpes simplex (types I and II) virus;

- Acute viral intestinal infections caused by calicivirus, coronavirus, or rotavirus;

- And demonstrated its therapeutic effects in tick-borne encephalitis, pseudotuberculosis, yersiniosis, whooping cough, haemorrhagic fever with renal syndrome, tubulo-interstitial nephritis, enteroviral and meningococcal meningitis, chlamydial infection, epidemic parotitis, enterovirus infections (Coxsackie A and B viruses, ECHO).

Due to its immunomodulatory activity in addition to the marked antiviral effect, anaferon can be successfully used in infections secondary to immunodeficiencies, and for managing chronic infections, which are particularly refractory to treatment as a result of high virus mutability and their ability to suppress the immune response [22].

The clinical evidence accumulated is indicative of a high safety of anaferon, including when administered in young children (neonates and older infants): no serious drug-related adverse events have been reported; it is safe in patients with co-existing conditions, including children with atopic disease (allergic rhinitis, allergic conjunctivitis, atopic dermatitis, acute urticaria), and specifically - noninfectious and infectious allergic (atopic) asthma. Owing to its high safety, anaferon has a number of advantages over recombinant interferons, which may produce complications.

In summary, the numerous nonclinical and clinical studies conducted have demonstrated that anaferon has a broad range of antiviral and antibacterial activities, which, given almost no adverse events due to the drug, make it a product of choice for treating infectious diseases of different etiologies (including in infants $<1$ year of age), and infections in the presence of underlying medical conditions.

\section{Acknowledgment}

Original Russian Text (C) S.A. Tarasov, M.V. Kachanova, E.A. Gorbunov, J.A. Zabolotneva, I.A. Kheifets, M.V. Belopolskaya, M.V. Borodavkina, J.L. Dugina, S.A. Sergeeva, O.I. Epstein, Anaferon Effective Medicine for Treatment and Prophylaxis a Wide Spectrum of Infections, 2010, published in Vestnik Mezhdunarodnoj akademii nauk. Russkaya sekciya, 2010, No. 1, pp.23-27.

The authors would like to thank S.A. Sergeeva $(2015)^{\dagger}$ for successful long-term management of OOO "NPF "MATERIA MEDICA HOLDING", Moscow, Russian Federation. Also the authors would like to thank V.V. Grechenko for the Figure 1 preparation (OOO "NPF "MATERIA MEDICA HOLDING”, Moscow, Russian Federation).

\section{Funding information}

The work was supported by grant from OOO "NPF "MATERIA MEDICA HOLDING”, 3rd Samotyochny per., 9, 127473, Moscow, Russian Federation. 


\section{Competiting interest}

The authors declare that they have no competing interests.

\section{References}

1. WHO (2016)The top 10 causes of death. World Health Organization.

2. Baron S (1996) Chemotherapy of Viral Infections. University of Texas Medical Branch at Galveston.

3. Meager A (2006)The Interferons: Characterization and Application.Wiley.

4. Epstein OI (2013) [The phenomenon of release activity and the hypothesis of "spatial" homeostasis]. Usp Fiziol Nauk 44: 54-76.[Crossref]

5. Gavrilova ES, Bobrovnik SA, Sherriff G, Myslivets AA, Tarasov SA, et al. (2014) Novel approach to activity evaluation for release-active forms of anti-interferon-gamma antibodies based on enzyme-linked immunoassay. PLoS One 9: e97017.[Crossref]

6. Don E, Farafanova O, Pokhil S, Barykina D, Nikiforova M, et al. (2016) Use of Piezoelectric Immunosensors for Detection of Interferon-Gamma Interaction with Specific Antibodies in the Presence of Released-Active Forms of Antibodies to Interferon-Gamma. Sensors 16: s16010096.

7. Verevshchikov VK, BorzunovVM, Shemyakina EK (2006) An experience of using Anaferon in a complex therapy of acute respiratory diseases in adults. Infectious Diseases 4: 88-90.

8. Kaira AN, Yushchenko GV, Akhmadullina RR, Cherkasova NA (2005) Nonspecific prophylaxis of influenza and acute respiratory viral infections with anaferon in the Moscow region. Infectious Diseases 4: 64-67.

9. Uchaykin VF (2003) Anaferon for children: domestic immunocorrector with antiviral activity. A manual for pediatricians and infectious diseases specialists, Moscow.

10. Chuvirov GN, Markova TP (2004) Antiviral therapy in influenza treatment. Russian medical journal 12: 1216-1218.

11. Korovina NA, Zaplatnikov AL, Burtseva EI, Malakhov AB, Kondyurina EG, et al. (2007) Treatment and prevention optimization of viral infections in children. Polyclinic 2: $8-11$.
12. Osidak LV, Afanasieva OI, Golovacheva EG, Milyeint KK, Obraztsova EV, et al. (2004) Experience of applying "anaferon for children" in therapy of respiratory syncitial virus (RSV) infection in children. Book of abstracts of the 3d Russian pediatricinfectionists congress, "Relevant issues of infection pathology in children. Infection and immunity". Moscow p: 175 .

13. Timchenko VN, Pavlova EB, Dzhangavadze ND (2006) Prevention and treatment of ARVI in HIV-positive children, with perinatal HIV-infection contact using "anaferon for children". Pediatric infections Supplement: 169-170.

14. Perevoshchikova NK, Basmanova ED, Kazanskaya TV (2006) Anaferon for children in rehabilitation programme for frequently ill children suffering from ARVI affected by pharyngeal lymphoid ring pathology. Pediatry 6: 65-69.

15. Kondyurina EG, Elkina TN, Shteynberg MV (2006) Prevention of respiratory infections in case of bronchial asthma in children aged 1 to 5 years. Pediatry 5: 72-76.

16. MartyushevPoklad AV, Kudin MV, Dyldina NV (2005) A novel therapeutic for treatment of varicella: peroral anti-interferon gamma antibodies. Book of abstracts of the 4th world congress of the world society for pediatric infectious diseases -WSPID. Warsaw, Poland p: 144

17. Vladimirtseva IF, Rusakova NV, Kurkina AV (2005) Specifics of tubulo-interstitia nephritis treatment in children in ambulance situation. Modern pediatry issues 4: 92.

18. Shulzhenko AE, Zuykova IN (2005) Anaferon's efficacy in patients with chronic recurrent herpes virus infection. Book of abstracts of the 7th Russian national "Man and Medicine" congress.

19. Strebkova EA (2007) Application of immunomodulatoranaferon in treatment of patients with ophthalmic herpes. Book of abstracts of the 14th Russian national "Man and Medicine" congress.

20. Fomin VV, Tunkina EE, Saburova EB (2004) Clinical and immunological assessment of anaferon's efficacy in complex therapy of infectious mononucleosis in children. Russian immunological journal 9: 185.

21. Skripchenko NV, Morgatskiy NV, Ivanova GP, Aksenov OA, Ivanova MV, et al. (2007) Contemporary possibilities of extra nonspecific prophylaxis of tick-born encephalitis in children. Pediatricheskaya Farmakologiya 7: 23-26.

22. Khaitov RM (2001) Immune system physiology. VINITI of RAS, Moscow.

Copyright: $₫ 2016$ Tarasov SA. This is an open-access article distributed under the terms of the Creative Commons Attribution License, which permits unrestricted use, distribution, and reproduction in any medium, provided the original author and source are credited. 